\title{
O DEBATE INSTITUCIONAL SOBRE RODOVIAS NA AMAZÔNIA: O CASO DA BR-319
}

\author{
Thiago Oliveira Neto ${ }^{1}$ \\ Ricardo Jose Batista Nogueira ${ }^{2}$
}

\section{Resumo}

Os revigoramentos dos eixos rodoviários existentes na Amazônia sempre foi visto pelos ambientalistas, pesquisadores e pelas instituições do próprio Estado como um vetor capaz de propiciar o avanço do desmatamento na região. O presente trabalho busca analisar esses impasses existentes no âmbito institucional, tendo como objeto geográfico particular de analise a recuperação de BR-319 entre as cidades de Manaus e Porto Velho. Para elaboração deste texto utilizou-se largamente de fontes constituídas na década de 70 e da atualidade.

Palavras chaves: rodovia, BR-319, Amazônia.

\section{THE CONSTITUTIONAL DEBATE ON HIGHWAYS IN THE AMAZON: THE CASE OF BR-319}

\begin{abstract}
The empowerments of existing roads in the Amazon has always been seen by environmentalists, researchers and the institutions of the state itself as a vector capable of providing the advance of deforestation in the region. This study seeks to analyze these existing impasses at the institutional level, with the particular geographic object to analyze the recovery of BR-319 between the cities of Manaus and Porto Velho. To this writing was used widely supplies made in the 70s and today.
\end{abstract}

Key words: highway, BR-319, Amazon.

\section{LE DEBAT CONSTITUTIONNEL SUR LES ROUTES EN AMAZONIE: LE CAS DU BR-319}

\section{Résumé}

Les habilitations des routes existantes en Amazonie a toujours été vu par les écologistes, les chercheurs et les institutions de l'Etat lui-même comme un vecteur capable de fournir l'avance

\footnotetext{
${ }^{1}$ Mestrando em Geografia pela Universidade Federal do Amazonas. E-mail: thiagoton91@live.com.

${ }^{2}$ Professor do departamento de geografia e do Programa de Pós-Graduação em Geografia da Universidade Federal do Amazonas. E-mail: nogueiraricardo@uol.com
}

Sociedade e Território - Natal. Vol. 29, N. 1, p. 84 - 101 .Jan./Jun. de 2017 
de la déforestation dans la région. Cette étude vise à analyser ces impasses existantes au niveau institutionnel, avec l'objet géographique particulière pour analyser la reprise du BR319 entre les villes de Manaus et Porto Velho. Pour cette écriture a été largement utilisé ponts construits dans les années 70 et aujourd'hui.

Mots clés: autoroute, BR-319, Amazon.

\section{INTRODUÇÃO}

Na primeira década do século XXI, observa-se uma retomada por parte do Estado da construção e reconstrução na Amazônia de eixos de circulação implantada desde a década de 1960 quando se constrói a rodovia Belém-Brasília, pois estes objetos geográficos -vias de circulação- sempre se constituíram como estruturas fundamentais de políticas territoriais, seja voltadas à defesa, seja destinada à articulação do território de um Estado. Por isso mesmo foi tema de preocupação dos clássicos da geografia política. Isto justifica o fato de que instituições do próprio Estado brasileiro tenham participado de estudos ambientais e técnicos sobre construção das rodovias na região. O impasse se instaura a partir de prerrogativas apoiadas, muitas vezes, no vetor ambiental, que é sempre o elemento de maior preocupação de uma boa parte dos intelectuais, ambientalistas.

Uma das maiores tramas vivenciadas neste contexto de consolidação dos eixos rodoviários na Amazônia, é o revigoramento da rodovia BR-319, entre as cidades de Manaus e Porto Velho. Essa rodovia possui 857 quilômetros, dos quais 405 necessitam ser pavimentados para propiciar o fluxo continuo de qualquer veículo. Entretanto, essa reconstrução esbarra em prerrogativas estabelecidas pelo próprio Estado, a partir de suas instituições.

Nesse contexto, o desafio deste artigo é propor uma discussão no que tange à reconstrução da BR-319 e o debate institucional entre o Ministério dos Transportes-M.T e o Ministério do Meio Ambiente-M.M.A, ocasionado pela possibilidade de reestabelecer o fluxo contínuo de veículos entre as cidades de Manaus e Porto Velho, debate este motivado por divergências na condução de políticas adotadas pelos ministérios, que tem como fundo a concepção de Estado distinta para cada grupo de interesses. Para tanto, faz-se uma breve abordagem histórica sobre a construção e desestruturação da rodovia e, em seguida, apontamse os debates institucionais que envolvem a reconstrução da ligação terrestre de Manaus com o sistema viário nacional. 
Como metodologia, houve uma necessidade de recuperar fontes (revistas, imagens e vídeos) da década de 1970 para identificar ações, sujeitos e o entusiasmo do período para a conquista da Amazônia. Também recorreu-se a trabalhos pioneiros sobre a BR-319 como o de Freire (1985); as analises de clássicos da geopolítica como Maull (1960) que ressalta os fundamentos da circulação sobre o território; além das contribuições de Becker (2001, 2005). Para a exposição do debate institucional, o recurso à internet foi primordial, não apenas aos sites dos respectivos órgãos como a busca em jornais e outros veículos de divulgação. Enfim, os documentos estudos de impactos ambientais e os relatórios de impactos ambientaisEIA/RIMA elaborados pela Universidade Federal do Amazonas-UFAM e os debates com pesquisadores da região com posições divergentes sobre essa gigantesca rodovia, compuseram a base para a elaboração do artigo.

\section{CONSTRUÇÃO E SECÇÃO NOS FLUXOS NA MANAUS-PORTO VELHO}

A ligação rodoviária entre as cidades de Manaus e Porto Velho foi materializada durante o regime militar, quando se objetivava integrar o território nacional e povoar a Amazônia, com uma perspectiva geopolítica clássica, que consistia em: integração, povoamento e segurança nacional das fronteiras, além de promover o desenvolvimento econômico. Vale aqui destacar, com relação a este último objetivo citado, que a construção deste objeto geográfico ocorreu quando se instalava, em Manaus, o parque industrial e a área de livre comércio de importação.

As obras de construção do eixo rodoviário ocorreram entre junho de 1968 até o início de 1976, ano da inauguração. Naquele momento, a estrada Manaus-Porto Velho foi apontada, pelos jornais da época, como uma das mais difíceis obras de engenharia do Brasil. A cidade de Manaus possuía 350.000 habitantes enquanto Porto Velho 100.000.

A rodovia BR-319 exerceu um papel fundamental de integração territorial após 1973. Desde então, um fluxo contínuo e constante de veículos passou a existir entre as cidades e vilas ao longo do traçado rodoviário, num fluxo composto pelas linhas de ônibus que interligaram a capital da Zona Franca as rodoviárias de São Paulo, Porto Alegre, Brasília, Cuiabá e Porto Velho. Não se pode deixar de fora uma referência ao transporte de carga, que, apesar dos rios Amazonas e Madeira servirem-se claramente como via de ligação, uma parcela significativa do transporte de produtos alimentícios e de componentes para o Polo 
Industrial e Área de Livre Comercio de Manaus era transportada pelo modal rodoviário até o início da década de 90.

A partir de 1981, diversos empecilhos contribuíram para tornar a rodovia, até então inteiramente pavimentada, numa via intrafegável. Conforme destaca, Oliveira Neto (2014), os cinco principais fatores que estão diretamente associados à secção dos fluxos entre as capitais regionais, foram: excesso de peso dos veículos; crise econômica no final da década de 70 , limitando investimentos em infraestrutura e corroborando com a ausência de manutenção; elevados índices pluviométricos; aterros da rodovia possivelmente foram realizados com a presença de matéria orgânica (raízes, galhos, troncos de árvores); retirada de trechos do pavimento por uma construtora ${ }^{3}$.

A partir de meados da década de 90, aconteceram várias tentativas fracassadas de reabertura ao tráfego por meio de programas de infraestrutura, tais como os planos plurianuais-PPA: Brasil em Ação (1996-1999), Avança Brasil (2000-2003), Plano Brasil de Todos (2003-2007), Programa de Aceleração do Crescimento-PAC 1 (2007-2010) e PAC 2 (2011-2014). Somente nos últimos programas governamentais, ações concretas, voltadas para conclusão das obras, foram realizadas. Atualmente, porém, o problema para reativação dos fluxos no modal não se permeia pela falta de recurso, mas pelos entraves e empecilhos criados por instituições do próprio Estado e/ou por aquelas não governamentais, inviabilizando a integração territorial.

\section{O DEBATE INSTITUCIONAL DA RECONSTRUÇÃO DA RODOVIA MANAUS- PORTO VELHO}

No século XXI, observa-se a consolidação da proposta estabelecida no final do século XX, que consistia em revigorar os grandes eixos de circulação nacional, sendo alguns destes situados na Amazônia brasileira. Diante dos processos acelerados de integração na América do Sul, iniciado com o bloco Mercado Comum do Sul-Mercosul, e a forte tendência de ampliar fluxos para todo o continente, a Amazônia aparece como centro do centro do continente. Conforme aponta Thery (2005), os fluxos continentais e regionais perpassam pelo

\footnotetext{
3“'A rodovia funcionou até 1988. Muitos dizem que não houve manutenção e ela acabou. Mas quem mora ao longo da BR tem outra história para contar. Afirma que a estrada foi destruída por dinamites. Na época não houve investigações sobre as denúncias. Mas os moradores dizem que tinha "gente poderosa", que não queria ver a estrada funcionando. "Vi a estrada boa, boa, boa; e vi tirando [destruindo]. Eu vi o cara chegando e metendo o trator. [...] assassinaram a BR", disse a parteira Tereza Alves. Fonte: <http://g1.globo.com/am/amazonas/noticia/2015/10/quase-40-anos-apos-inauguraçao-br-319-continuainacaba0no-am.html>
} 
interior do continente sul-americano, ou melhor, uma parte do transporte de carga e de passageiros se dá pelos meios técnicos e físicos existentes na Amazônia nacional e internacional. E mais, uma das formas de acentuar e consolidar esses fluxos dá-se por meio do revigoramento das rodovias existentes na Amazônia e de outros modais, tais como o ferroviário.

A conjuntura latino-americana, do ponto de vista ideológico, encaminha-se a um contexto de integração regional. Todas as correntes ditas "ideológicas" são unanimes a esse interesse em comum, calcada na interligação física dos países e, concomitantemente, dos blocos econômicos (MARTIN, 2011). E, nesse sentido, a Amazônia está diretamente inserida nesta conjuntura internacional tanto quanto na nacional.

Contudo a consolidação dos eixos internacionais e nacionais de circulação esbarra atualmente em prerrogativas ambientais, constituídas em leis e decretos, a partir da década de 80, quando organismos internacionais que concedem financiamento às obras de infraestrutura passaram a solicitar, previamente, estudos de impacto ambiental dos empreendimentos financiados (BECKER, 2001). Neste contexto, todo empreendimento que se queira realizar exige Estudo de Impacto Ambiental-EIA e o Relatório de Impacto Ambiental-RIMA, tanto para instalação e operação de serviços, quanto para obtenção de recursos internacionais e nacionais.

Em decorrência da possibilidade de desmatamento, grilagem de terras e de ocupação, o projeto de revigoramento da rodovia Manaus-Porto Velho foi pensada como um caminho que possuísse, em suas respectivas margens, diversas unidades de conservação verdadeiro buffer zone, apontadas como uma preocupação do Estado quanto aos recursos naturais do seu território. Esta ação foi tomada após a suspensão das obras durante o primeiro PAC em que, como pré-requisito inicial para instalação do empreendimento e reinício das obras, o M.M.A, através de seu órgão IBAMA ter solicitado do M.T, através do DNIT ${ }^{4}$, um EIA/RIMA, na busca de verificar a viabilidade do projeto e os seus respectivos efeitos positivos e negativos ao longo de $857 \mathrm{~km}$ de rodovia, tendo ainda $405 \mathrm{~km}$ a serem recuperados.

Para sistematizar os fatos ocorridos, no que se refere à trama da possiblidade de reabertura/restauração da rodovia BR-319, buscou-se periodizar este estudo em quatro principais acontecimentos nos últimos 15 anos. O primeiro consiste nas ações do Programa Avança Brasil, em que o extinto Departamento Nacional de Estradas de Rodagem-DNER

\footnotetext{
${ }^{4}$ Departamento Nacional de Infraestrutura de Transporte.
} 
realizou a licitação da recuperação de trechos da rodovia, tendo como empresa vencedora a Gautama, porém irregularidades no contrato e danos ambientais resultaram na paralisação das obras em 2007 (TERRA, 2007; CLIPPING, 2007). Naquele momento não se tinha um estudo aprofundado de impacto ambiental das obras do empreendimento.

O segundo momento se estabelece a partir do ano de 2005, quando o governo continua realizando ações voltadas para concluir os eixos de integração territorial. Naquele momento, iniciaram-se discussões aprofundadas sobre os possíveis impactos ambientais e sociais, e criou-se a Área sob Limitação Administrativa Provisória-ALAP BR-319 em 2006 demonstrando, de forma clara, o poder do Estado na criação de uma regionalização via instituição jurídica e formal ${ }^{6}$. No quesito de instituição e delimitação de área, criou-se uma região para fins institucionais-políticos, visando, a priori, a preservação de uma porção territorial, que compreendesse pelas margens da rodovia BR-319 até os rios Madeira e Purus.

Para efetivar a preservação, utilizou-se como mecanismo principal a demarcação de outras frações territorial da ALAP, por meio da institucionalização de 21 Unidades de Conservação, assim distribuídas: 11 de âmbito federal; 10 sob administração estadual (SOAVINSKI, 2009; ICMBIO, 2015). Esse quadro mostra, de forma clara, a gestão de políticas públicas territoriais ${ }^{7}$ com abordagem ambiental, como, por exemplo, criação de unidades de conservação ${ }^{8}$, terras indígenas e medidas voltadas à recuperação de áreas degradas pelo empreendimento.

A terceira ponderação dessa periodização destaca as ações ocorridas a partir de 2007, quando houve a reestruturação parcial da rodovia no sentido de apenas torná-la trafegável às equipes que implantavam fibra óptica entre as cidades de Manaus e Porto Velho. Desse modo, assim como as rodovias, as redes de telecomunicação ${ }^{9}$ constituíram-se numa integração de

\footnotetext{
${ }^{5}$ Em 02/01/2006 por meio do Decreto Presidencial foi criada a ALAP - Área de Limitação Administrativa Provisória da região da BR-319 (Interflúvio dos rios Madeira e Purus, entre Porto Velho/RO e Manaus/AM). Disponível em: <http://www.mma.gov.br/estruturas/sbf/_arquivos/folder_consulta1.pdf>.

${ }^{6}$ A este respeito ver Nogueira (2011).

${ }^{7}$ Costa (1996) considera que a política territorial pode ser qualquer atividade estatal que implique em uma concepção do espaço nacional, em uma estratégia de intervenção ao nível da estrutura territorial e por fim, contenha mecanismos concretos, capazes de torná-las viáveis (apud MELLO-THERY, 2011, p. 29).

${ }^{8} \mathrm{O}$ aumento das Unidades de Conservação públicas (Ucs), das reservas privadas de patrimônio natural (RPPN) e dos territórios indígenas é reflexo da pressão de ONG[s] que avançam e operacionalizam a própria política, que agem em redes de solidariedade, ao lado de sindicatos e outros atores. São atores de peso, associados ao vetor ecológico, processo em curso especialmente na Amazônia (MELLO-THERY, 2011, p. 33).
}

\footnotetext{
${ }^{9}$ Para melhor compreensão do significado territorial das redes técnicas ver Dias (2012).
} 
todos os pontos do território, porém sua implantação, no caso particular, dependeu da existência da rodovia, assim como da manutenção desta para propiciar a manutenção das torres e dos cabos de telecomunicação. Deve-se apontar que a Empresa Brasileira de Telecomunicações-EMBRATEL mantém, hoje, equipes permanentes de trabalho de manutenção dos equipamentos, realizando, porém, nos últimos anos, a manutenção nas pontes de madeira e tapa-buraco, evitando o colapso total da rodovia.

Além da implantação da fibra óptica, houve ações voltadas à preservação ambiental, como a sinalização da primeira unidade de conservação no ano de $2009^{10}$.

O período entre 2009-2015 compreende como o quarto acontecimento, o último recorte temporal, tendo como elemento chave o fim do primeiro PAC e a vigência do segundo PAC. Nesse período, foram realizadas diversas medidas voltadas à minimização de possíveis impactos ambientais, e realizaram-se inúmeras pesquisas voltadas à fauna e flora, bem como foram criadas inúmeras unidades de conservação, fruto das políticas conservacionistas, que instituíram uma enorme fração territorial ao longo da rodovia, entre o interflúvio dos rios Madeira e Purus (fig. 1), estendendo-se num total de 1,8 milhões de hectares de áreas protegidas, visando criar uma armadura aos possíveis avanços do desmatamento.

\footnotetext{
10 “O Serviço Geográfico do Exército brasileiro [concluiu em 2009] a sinalização da primeira placa e do primeiro marco no Parque Estadual do Tapauá, uma das 27 unidades de conservação criadas no entorno da BR319. Ao todo, serão instalados 5 mil marcos nestes parques, além de placas de sinalização informativas para demarcar a área das unidades, que soma quase 12 milhões de hectares". Disponível em: <http://www.bbc.com/portuguese/noticias/2009/10/091029_asfaltofloresta_exercito_ec.shtml> Acesso em: 29 de set. de 2015.
} 
Figura 1: Unidades de Conservação entre o Interflúvio dos rios Madeira e Purus.

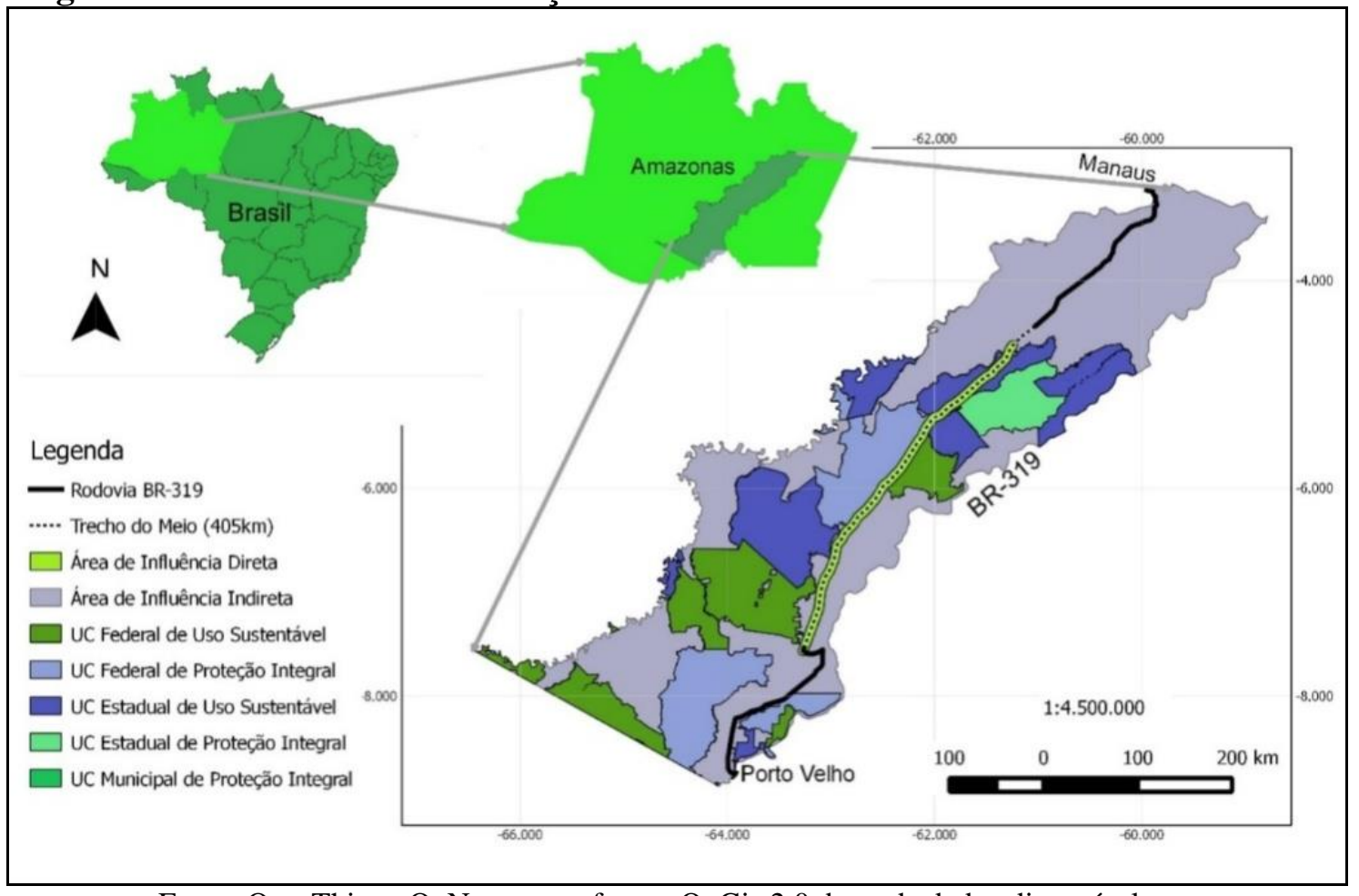

Fonte: Org. Thiago O. Neto em software Q. Gis 2.0, base de dados disponível em: <http://mapas.mma.gov.br/i3geo/datadownload.htm> Acesso em: 10 de out. de 2015.

A demarcação de frações territoriais em unidades de conservação é uma demonstração de uma forma de controle de uma área, este vai depender do esforço do enquadramento consentido, remetendo ao poder puro, que de acordo com Claval (1979) parte de uma organização particular do espaço, sendo possível efetivá-lo quando atrelado a um determinado controle permanente, e este, implica numa vigilância constante para alcançar o objetivo esperado através de um aparato capaz de propiciar o exercício do poder, seja através da "articulação do espaço em áreas contínuas, organização de sua vigilância, colocação de controles nos limites das circunscrições" (1979, p. 25).

Os embates constituídos na esfera federal, por meio de órgãos como IBAMA, que solicitava constantemente complementos ao relatório de impacto do DNIT, emperraram os avanços das obras de manutenção e recuperação total da rodovia, em contrapartida, na esfera estadual, criou-se mecanismos jurídicos capazes de intervir diretamente na recuperação da rodovia. Neste contex to de entraves burocráticos entre órgãos federais, o Estado do Amazonas utilizou-se de prerrogativas legais e institui a partir da Lei $N^{\circ} 3785$ de setembro de 2012, a criação da Licença Ambiental Única-LAU. 
Recentemente, o embate federativo resultou com a liberação das obras de reconstrução da rodovia através de uma LAU, emitida pelo Instituto Ambiental do AmazonasIPAAM, permitindo as atividades de manutenção.

Tal medida não permitiu a pavimentação total da rodovia, contudo propiciou manutenção das pontes e as melhorias na rodovia, constituindo uma diminuição no tempo de viagem entre as cidades situadas no eixo da rodovia e favorecendo o restabelecimento de fluxos contínuos e a mobilidade espacial dos moradores locais. O mesmo mecanismo foi utilizado para iniciar a recuperação da BR-174-Ramal Democracia, que interliga a BR-319 à cidade de Manicoré as margens do rio Madeira.

A partir deste mecanismo jurídico, as ações políticas de deputados de Rondônia e do senado federal "pressionaram" as demais autoridades, que compõem o corpo dos órgãos ambientais -IBAMA, para que fosse acelerada a liberação da analise final da Licença de Prévia-LP, e, consequentemente, a obtenção da Licença de Instalação-LI e da Licença de Operação.

Esta ação jurídica de criação da LAU demonstra a atuação dos estados na constituição de regimentos ambientais próprios, distintos ou similares às normas de órgãos e institutos de âmbito nacional. Foram alguns desses institutos nacionais, como o IBAMA, que criaram diversos entraves para a não recuperação da rodovia BR-319. Certamente isto evidencia a capacidade, o poder do Estado através do monopólio da legislação, de "fazer" o território que lhe for propicio. Numa republica federativa, em que há repartição territorial do poder, isto produz embates jurídicos sobre as ações politicas dos entes que compõem a federação. Isto na verdade, ainda precisa ser mais explorado pela geografia política, principalmente a brasileira, para compreender a relação política e território numa federação.

Em uma de suas colunas, o Jornal A Crítica de Manaus, questionou as ações do IBAMA, discutindo o fato de este ser um órgão de instancia nacional, que intervém radicalmente na possibilidade de reconstrução de $405 \mathrm{~km}$ da BR-319, aparentando uma contramão a integração territorial nacional.

O mesmo jornal, ainda, apontou as críticas de políticos em relação ao IBAMA e a Lobby das empresas de navegação que exploram o serviço de transporte de cargas no rio Madeira ligando as cidades de Manaus e Porto Velho, que não querem dividir a carga com a rodovia. 
Francisco Souza disse que além do discurso ambiental "radical", outro fator que contribui para as diversas paralisações das obras da rodovia foram os interesses dos empresários do ramo da navegação, que ficariam prejudicados com a revitalização da BR $319^{11}$.

"Eles, inegavelmente, tem uma força porque dominam a logística de cargas entre Manaus, Rondônia e Belém. Mas não é por isso que vamos ficar parados e negando o novo modal. Faltava união para termos força política, agora temos", disse. (ACRÍTICA, 2015).

Esse quadro demonstra que "em todas as sociedades nacionais há grupos (...) [que] possuem interesses diferentes e muitas vezes conflitantes" (CASTRO, 2005, p. 40), ou seja,vê-se em jogo o interesse das empresas de ônibus, dos moradores das cidades conectadas pelo modal rodoviário, interesse do transporte fluvial pela não reativação da estrada com receio de perda de "clientes" e, por final,os interesses de instituições do próprio Estado, tendo vozes de políticos a favor da rodovia e ambientalistas contrários. Castro (2005) ressalta os conflitos de interesses de forma geral da seguinte maneira:

Neste sentido, é possível afirmar que as questões e os conflitos de interesses surgem das relações sociais e se territorializam, ou seja, materializam-se em disputas entre esses grupos e classes sociais para organizar o território da maneira mais adequada aos objetivos de cada um, ou seja, do modo mais adequado aos seus interesses. Essas disputas criam tensões e formas de organização do espaço (...) (CASTRO, 2005, p. 41).

Como medida associada ao vetor ambiental, tem-se a proposta de institucionalização da rodovia BR-319 no trecho de 400 km, como uma Estrada Parque-EP, inserindo-se, desse modo, no bojo das políticas conservacionistas. O princípio de uma EP é a conservação da fauna, flora e de cursos d'água, restringindo-se a passagem de veículos transportadores de produtos contaminantes. Torna-se um ambiente marcado pela preservação ambiental e favorável ao ecoturismo. Uma EP atende aos objetivos das instituições do Estado, promovendo o fluxo de pessoas e mercadorias pelo território e assegurando a preservação ambiental do contingente de florestas existentes no âmago do país.

Outra rodovia que se insere neste contexto de integração é a BR-174/ramal Democracia, com 84 km, que interliga a BR-319 à cidade de Manicoré. Essa rodovia funcionou plenamente no mesmo período em que ocorria a trafegabilidade da Manaus-Porto Velho, e, conforme foi diminuindo a manutenção da rodovia principal, concomitantemente,

\footnotetext{
${ }^{11}$ Tal assertiva não é um argumento atual. Na matéria sobre o transporte rodofluvial da Revista Transportes na Amazônia já apontava que "a reabertura da BR-319 (Manaus-Porto Velho) contribuíra para a queda no setor fluvial, especificamente no roll-on-roll-off e carga em geral” (1987, p. 6).
} 
ocorreu ausência de manutenção no acesso rodoviário secundário, implicando na suspensão das linhas de ônibus que partiam de Manaus, Porto Velho e Humaitá em direção à cidade de Manicoré. O processo de reconstrução dessa ligação rodoviária secundária ocorreu a partir de 2014, por meio da LAU No 394/14.

A circulação em um território ocorre por meio da existência de uma base física, capaz de propiciar o fluxo de mercadorias e pessoas. Os fluxos de pessoas e sua respectiva mobilidade é uma "necessidade da vida dos indivíduos e das coletividades" (CLAVAL, 2007, p. 21). De um lado, as rodovias assumem um papel estratégico, pois favorecem o fluxo de tropas no interior, por outro lado, estes objetos geográficos propiciam o fluxo de pessoas e de cargas geradas localmente para o litoral e os centros consumidores.

Apesar dos entraves jurídicos, institucionais e de grupos de interesses distintos, devese apontar que, para um Estado, a circulação é de extrema relevância. Deve-se, então, considerar melhor, partindo-se do ponto de vista geopolítico, que as redes físicas construídas propiciam a integração das diversas porções territoriais e seu povoamento, permitindo o domínio territorial do país, quando o mesmo detém uma malha de circulação eficiente (MAULL, 1960; MIYAMOTO, 1995).

Para o Exército, uma via com boa qualidade de trafegabilidade representa, do ponto de vista estratégico, possíveis ações e deslocamentos pontuais em menor tempo. E, do ponto de vista geopolítico, uma rodovia, não necessariamente, é (re)construída apenas voltada para fins econômicos, do transporte de carga ou de passageiros, o objeto geográfico pode ter valores atribuídos do ponto de vista estratégicos de defesa nacional.

\footnotetext{
A Doutrina Militar Terrestre estabelece que os órgãos envolvidos no apoio logístico às tropas em operações e que estão situados mais à retaguarda deverão realizar esse apoio por intermédio de um Eixo Prioritário de Transporte (EPT). O EPT deverá contemplar necessariamente vários modais de transporte, com intuito de flexibilizar a logística, criando, dessa forma, alternativas para o apoio às tropas em combate. $\mathrm{O}$ eixo Manaus-AM - Porto Velho-RO constitui um EPT de fundamental importância para as Forças Armadas, principalmente para o Exército Brasileiro. Atualmente, esse EPT dispõe apenas de dois modais: o aéreo e o hidroviário. Com a BR-319 ficando em condições de trafegabilidade, o EPT ficaria constituído de três modais de transporte, o que facilitaria sensivelmente o escoamento dos meios necessários para o apoio de forças em combate.
}

No que concerne aos tempos de paz, o Exército salienta que os modais aéreo e hidroviário, apesar de indispensáveis, apresentam desvantagens que comprometem a eficiência e a rapidez do apoio logístico. O transporte aéreo possui limitações de peso e volume, além de envolver altos custos. Segundo a $12^{\mathrm{a}}$ Região Militar, a aeronave C-105 tem custo da hora de voo de US\$ $3.312,20$ (três mil e trezentos e doze dólares e vinte centavos) com carga útil 
de 5,5 toneladas, ao passo que a aeronave C-130 tem custo da hora de voo de US\$ 2.920,00 (dois mil e novecentos e vinte dólares) com carga útil de 12 toneladas. No que concerne ao modal hidroviário os problemas dizem respeito à lentidão, uma vez que, em média, uma balsa do Centro de Embarcações do Comando Militar da Amazônia leva 9 dias para ir de Manaus a Porto Velho.

O Exército Brasileiro, por intermédio da $12^{\mathrm{a}}$ Região Militar, afirma que a BR-319 será uma alternativa que irá minimizar os problemas dos outros modais existentes (TCU, TC 015334/2009-5, pp. 3-4).

Com esse quadro, é possível apontar e contrapor a ideia simplista de que abrir ou reabrir uma rodovia na Amazônia depende da quantidade de veículos que vão passar, pois a concepção geopolítica não considera a relação "custo-benefício", própria aos empreendimentos privados, ou seja, não parte da quantidade de tráfego de veículos, mas do valor estratégico que um determinado objeto geográfico possui, como pode ver no caso da rodovia BR-319. Deve-se destacar também que, em decorrência da desproporção de densidade demográfica da Amazônia em relação às demais regiões do Brasil, e da própria diferença encontrada dentro da Amazônia, não é possível comparar o fluxo de veículos numa dada rodovia amazônica com as rodovias do centro-oeste, sudeste, nordeste e sul, pois são densidades demográficas e lugares completamente distintos. A métrica deve ser outra.

As dinâmicas, movimentos assim como as especificidades dos lugares são inteiramente distintos de um para outro, principalmente quando se trata de rodovia na Amazônia. Não dá para comparar certas dinâmicas, ações e ambientes situados em coordenadas diferentes, pois cada rodovia possui além de forma, função, processo, estruturas distintas uma das outras, apesar de terem sido construídas entre 1968-1976. A rodovia Transamazônica BR-230 e a Cuiabá-Santarém BR-163 tiveram projetos de colonização e incentivo maciço, voltados ao povoamento e desflorestamento, algo muito diferente do que se vê ao longo da BR-319, uma rodovia que possui núcleos populacionais nas margens da estrada, oriundos da travessia de balsa e poucos assentamentos. Outra diferenciação primordial consiste em que as rodovias citadas (BR-230 e BR-163) não foram pavimentadas imediatamente, porém comportaram projetos de colonização com a criação de vários ramais de acesso formando o processo denominado de "espinha de peixe"12, enquanto a rodovia BR319 foi inteiramente pavimentada, funcionou por uma década e não teve essa mesma espacialização vista pelas imagens obtidas pelos satélites artificiais.

\footnotetext{
${ }^{12}$ Decorrência de assentamentos e colonização.
} 
É lamentável que inúmeros cientistas ${ }^{13}$ pautem-se em exemplos do passado para condenar a abertura ou recuperação de estradas na Amazônia. Argumentam que haverá uma ampliação dos desmatamentos, conflito por terras, exploração madeireira e tantos outros malefícios. Para contestar tais argumentos deve-se argumentar que, em primeiro lugar, o desmatamento da região no passado, tendo como vetor a abertura das rodovias, foi estimulado pelo próprio Estado brasileiro, que financiou e estimulou a vinda de migrantes para os projetos de colonização, assim como grandes empresários para a agropecuária na região, cabendo aos índios e seringueiros resistirem à esta ação; em segundo lugar não havia política ambiental para nortear as ações, pois estava em pleno vigor o pensamento de ocupação da nova fronteira agrícola do país; em terceiro lugar, buscava-se uma integração inter-regional, cuja meta era ligar a Amazônia ao Brasil.

Hoje, praticamente quatro décadas depois, as mudanças substanciais nos processos de ordenamento territorial brasileiro, a questão ambiental e a inserção do Brasil no comercio mundial, devem servir como elementos balizadores para a abertura ou recuperação de estradas na região. Em primeiro lugar deve-se deixar claro que a pressão migratória para a região é muito inferior que a do passado; não há por parte do Estado brasileiro novos projetos de colonização e assentamento na região e o estimulo à migração; esta migração para a região amazônica tem sido mais para as cidades do que para o mundo rural; a Amazônia também participa da integração brasileira ao mercado mundial, e, numa integração sul-americana a Amazônia é central, ou seja, deverá ser cortada por diversos fluxos; sua população também tem direito à mobilidade ampla, rápida e irrestrita como em outras regiões do país, não ficando cativa, refém do transporte fluvial, lento e desconfortável; enfim, os mecanismos de controle ambiental instituídos pelo Estado podem determinar formas especificas de regulação para abertura destes empreendimentos.

O Estado brasileiro esteve presente ao longo da elaboração de projetos viários de integração territorial para a Amazônia. O princípio da integração do território pelas redes físicas se perpetua até o início do século XXI, apesar de as preocupações ambientais dominarem o discurso de instituições do próprio Estado. É mais do que evidente a semelhança dos projetos rodoviários elaborados antes do governo militar e implantados durante esse regime, bem como com os atuais projetos da Iniciativa para da Infraestrutura Regional SulAmericana-IIRSA e do Programa de Aceleração do Crescimento-PAC. A cartografia mostra

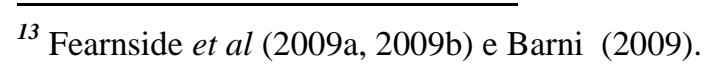

Sociedade e Território - Natal. Vol. 29, N. 1, p. 84 - 101 .Jan./Jun. de 2017 
isso, afinal os pontos de conexão permanecem praticamente os mesmos, referendando a ideia do condicionamento espacial.

$\mathrm{Na}$ atualidade, não basta diminuir as barreiras comerciais entre os países para estabelecer fluxos entre ambos, é necessário, primeiramente, a existência de uma estrutura capaz de possibilitar esses fluxos entre os territórios, seja uma ponte entre duas cidades fronteiriças ou uma rodovia entre os centros políticos e econômicos, interligando-os às fronteiras, propiciando, desta maneira, uma base física para existência dos fluxos comerciais e de pessoas entre os países.

\section{CONSIDERAÇÕES FINAIS}

Após quarenta anos da inauguração desta rodovia, a Amazônia encontra-se diante de uma conjuntura bem distinta daquele período. Para alguns a noção de "economia de fronteira" já foi superada e substituída pela noção de fronteira do capital natural (BECKER, 2005). Para outros, a Amazônia ganhou o status de centro da América do Sul, por sua localização. Para ambos os pensamentos, está em questão à rede de circulação a ser consolidada na região, em que a BR-319 é parte fundamental dos fluxos. Manaus, Hoje com dois milhões de habitantes e Porto Velho com quinhentos mil, querem integra-se, pressionando para isso.

Do que foi exposto ao longo do texto, acreditamos ser importante destacar que os embates internos às instituições governamentais revelam o quão problemático é a composição partidária para o exercício do governo. A distribuição de cargos entre aliados com perfis ideológicos distintos remetem a conflitos internos. O uso da rodovia BR-319 é emblemático neste sentido: opõe pensamentos divergentes travando ações do Estado.

A secção na rodovia BR-319 promoveu o rompimento de inúmeros fluxos e diversas redes, sejam elas de relações sociais ou de transporte, propiciando uma mudança no fluxo que, naquele momento, era rodoviário, passando a se intensificar no fluvial, pela hidrovia do rio Madeira. Ora, a substituição de um modal pelo outro implica diversas escalas, no lugar e no território, seja na estruturação de objetos geográficos capazes de propiciar o fluxo, no caso a construção de portos, o mapeamento constante e a dragagem do rio. Por outro lado, representa, ainda, o abandono dos lotes de colonos e moradores que habitavam às margens da rodovia, ocasionando uma desterritorialização e uma nova territorialidade em outros lugares.

Esta rodovia já abrigou no passado inúmeros serviços -hotéis, posto de combustível, restaurantes e oficinas- que davam apoio aos seus usuários e moradores dos núcleos 
habitacionais, vilas e cidades. Todas essas atividades deixaram de existir com a interrupção do tráfego. Hoje, num mundo em que se exige velocidade, instantaneidade, aceleração dos fluxos, das tropas, a intensificação dos multimodais em diversas escalas, é imperioso consolidar este circuito de circulação na Amazônia, acreditando que do embate institucional só sairão vencedores.

Tentamos deixar evidente que aqueles que se posicionam contrários à reabertura da rodovia, estruturam seus palpites e reflexões em pressupostos vencidos e apoiados em números dos desmatamentos em outras rodovias federais que entrecortam a Amazônia brasileira. Eles sempre apontam o desmatamento ao longo da BR-230 e BR-163, porém esquecem que nessas rodovias houve, de forma maciça, investimento do Estado e incentivo à colonização, mineração e demais práticas espaciais, algo que, por sinal, não ocorreu nas margens da totalidade da BR-319.

Com a consolidação, a rodovia BR-319 pode se tornar, ao longo das décadas, um objeto geográfico detentor de uma tecnicidade simétrica, em que se instauram relações não destrutivas do meio natural. Porém o abandono e a ausência de fiscalização resulta como incentivo às práticas predatórias, como extração de recursos naturais, à formação de novas fazendas, com queimadas que se constituem em uma tecnicidade dissimétrica, marcada pelas relações destrutivas do meio natural, indo na contramão das políticas ambientais que o país adotou a partir da década de 80 .

Enfim, apesar dos embates técnico/federativo/político referentes à rodovia, nota-se um forte interesse da sociedade em circular pelo território, seja de ônibus ou de carro. Recentemente, reiniciaram-se as viagens de ônibus entre Manaus-Humaitá-Porto Velho, após duas décadas sem transporte de passageiros. Com as melhorias, o fluxo de veículos torna mais rápidas as viagens entre os lugares, além de facilitar o deslocamento, também mais ágil, do exército pelo interior do território, em sua atividade de segurança.

\section{REFERÊNCIAS}

ACRÍTICA, Expedição parlamentar vai fiscalizar obras da BR-319. Disponível em: <http://acritica.uol.com.br/amazonia/a_0_1443455671.html> Acesso em: 11 de out. de 2015.

AMAZONAS. Lei no 3785, de 25/07/2012. Disponível em: < http://www.legisweb.com.br/legislacao/?id=243659> Acesso em: 22/09/2015.

AMAZONAS. LAU, nº 394 de 25 de agosto de 2014. 
AMAZONAS. LAU, nº 422 de 25 de agosto de 2014.

BARNI, Paulo Eduardo. Reconstrução e asfaltamento da Rodovia BR-319: Efeito “dominó" pode elevar as taxas de desmatamento no Sul do Estado do Amazonas. 2009. Dissertação (Mestrado em Ciências de Floresta Tropicais) - Programa de Pós-graduação Ciências de Floresta Tropicais, INPA, Manaus.

BECKER, Bertha K. Revisão das políticas de ocupação da Amazônia: é possível identificar modelos para projetar cenários? Parcerias Estratégicas, n. 12, p. 135-159. 2001.

BECKER, Bertha K. Geopolítica da Amazônia. Estudos Avançados, nº 19, Vol. 53, pp. 7186, 2005.

CASTRO, Iná Elias. Geografia e Política: Território, escalas de ação e instituições. Rio Janeiro: Bertrand, 2005.

CLIPPING, Gautama fere lei ambiental, diz ministério Disponível em:

$<$ http://noticias.ambientebrasil.com.br/clipping/2007/06/19/31844-gautama-fere-leiambiental-diz-ministerio.html> Acesso em: 11 de out. de 2015.

CLAVAL, Paul. Espaço e Poder. Rio de Janeiro: Zahar Editores, 1979.

CLAVAL, Paul. A geografia cultural. Trad. Luíz Fugazzola Pimenta e Margareth de Castro A. Pimenta. Florianópolis: Editora da USFC, 2007.

DIAS, Leila Christina. Redes: emergência e organização. In CASTRO, Iná de; GOMES, Paulo Cesar da Costa e CORRÊA, Roberto Lobato. (Org.). Geografia: Conceitos e Temas. $15^{\mathrm{a}}$ ed. Rio de Janeiro: Bertand, 2012. p. 141- 162.

FEARNSIDE, Philip M; GRAÇA, Paulo Maurício Lima de Alencastro. BR-319: a rodovia Manaus Porto Velho e o impacto potencial de conectar o arco de desmatamento à Amazônia central. Novos Cadernos NAEA, n. 1, v. 12, p. 19-50, jun. 2009a.

FEARSIDE, Philip Martin; GRAÇA, Paulo Maurício Lima de Alencastro; KEIZER, Willen Hermanus; MALDONADO, Francisco Darío; BARBOZA, Reinaldo Imbrozio; NOGUEIRA, E Euler Melo. Modelagem de desmatamento e emissões de gases de efeito estufa na região sob influência da rodovia Manaus-Porto Velho (BR-319). Revista Brasileira de Meteorologia, v. 24, n. 2, p. 208-233, 2009b.

FREIRE. Maria Amélia Alcântara. A Política Rodoviária e a BR-319: Os custos de uma Decisão. 1985. 127f. Dissertação (Mestrado em Sociologia Política) - Programa de Pósgraduação de Ciências Sociais da Fundação Escolar de sociologia e Política de São Paulo, PUC, São Paulo -SP, 1985.

HARTSHORNE, Richard. Propósitos e Natureza da Geografia. Trad. Thomaz N. Neto. São Paulo: HUCITED, 1978.

ICMBIO. Disponível em: <http://www.icmbio.gov.br/portal/comunicacao/noticias/20geral/4233-diagnostico-vai-subsidiar-a-elaboracao-de-11-planos-de-manejo.html> Acesso em: 11 de out. de 2015 . 
MARIA, Tanair. 2014. BR-319 é fundamental para baixar custos de logística do Amazonas, diz José Melo. Disponível em: < http://portalamazonia.com/noticias-detalhe/cidades/br-319-efundamental-para-baixar-custo-de-logistica-do-amazonas-diz-josemelo/?cHash=d5d74a4f881604a8f2ec9d465f3309ae>

MARTIN, André Roberto. Sopa de letrinhas: Alba, Alca, Mercosul, Unasul, Can... Para onde vai a integração Latino-Americana? In: ARROYO, Monica; ZUSMAN, Perla. Argentina e Brasil: Possibilidades e obstáculos no processo de integração territorial. São Paulo: Humanitas; Buenos Aires: Facultad de Filosofía y Letra, 2010. Pp. 37-57

MAULL, Otto. Geografía Política. Trad. Ismael Antich. Barcelona: Ediciones Omega Casa Nova, 1960.

MELLO, Neli Aparecida de; THÉRY, Hervé. A armadura do espaço Amazônico: eixos e zoneamentos. ALCEU, V. 1, N. 1, 2001, pp. 181-214.

MELLO, Neli Aparecida de. Território e gestão ambiental na Amazônia. Terras públicas e os dilemas do Estado. São Paulo: Annablume, 2011.

MIYAMOTO, Shiguenoli. A questão Ambiental e as Relações Internacionais. Inf. Legisl. Brasília, v.28, n. 112, pp. 107-132, 1991.

Geopolítica e Poder no Brasil. São Paulo: Papirus, 1995.

NOGUEIRA, Ricardo Jose Batista. Política e território: a invenção da região metropolitana. Somalu, no 11, vol. 2, pp. 175-189.

OLIVEIRA NETO, Thiago. A Geopolítica rodoviária na Amazônia: BR-319. Revista de Geopolítica, V. 5, n 2, pp. 109-128, 2014.

RAFFESTIN, Claude. Por uma Geografia do Poder. Trad. Maria Cecília França. São Paulo: Ática, 1993.

SANTOS, Milton. Por uma Geografia Nova: Da crítica da Geografia a uma Geografia Crítica. $2^{\text {a }}$ Ed. HUCITEC: São Paulo, 1980.

SOAVINSKI, Ricardo. Unidades de Conservação na área de influência da BR-319. Disponível em: <http://4ccr.pgr.mpf.mp.br/atuacao/encontros-e-eventos/audienciapublica/audiencia-publica-br-319/unidades_de_conservacao_br-319.pdf $>$ Acesso em: $11 \mathrm{de}$ out de 2015.

SOCIOAMBIMETAL. Decisão da Justiça Federal paralisa obras de recuperação da rodovia BR-319 (Manaus-Porto Velho) 2005. Disponível em: <http://siteantigo.socioambiental.org/nsa/detalhe?id=2064> Acesso em: 12 de out. de 2015 .

TCU, TC 015334/2009-5, 43. P.

TERRA 2007. Contrato com a Gautama é cancelado pela União. 01 de junho de 2007. Disponível em: <http://noticias.terra.com.br/brasil/noticias/0,,OI1662127-EI306,00-

Contrato+com+a+Gautama+e+cancelado+pela+Uniao.html $>$ Acesso em: 11 de out de 2015.

THERY, Hervé. Situações da Amazônia no Brasil e no continente. Revista Estudos Avançados, V. 19, N. 53, pp. 37-49. 2005.

Sociedade e Território - Natal. Vol. 29, N. 1, p. 84 - 101 .Jan./Jun. de 2017 
TRANSPORTES NA AMAZÔNIA. Rodofluvial: sob a crise passageira. Ano 1, n 3 . Manaus: Garcia, 1987.

Recebido em Maio de 2016

Aprovado em Fevereiro de 2017

Publicado em Agosto de 2017 